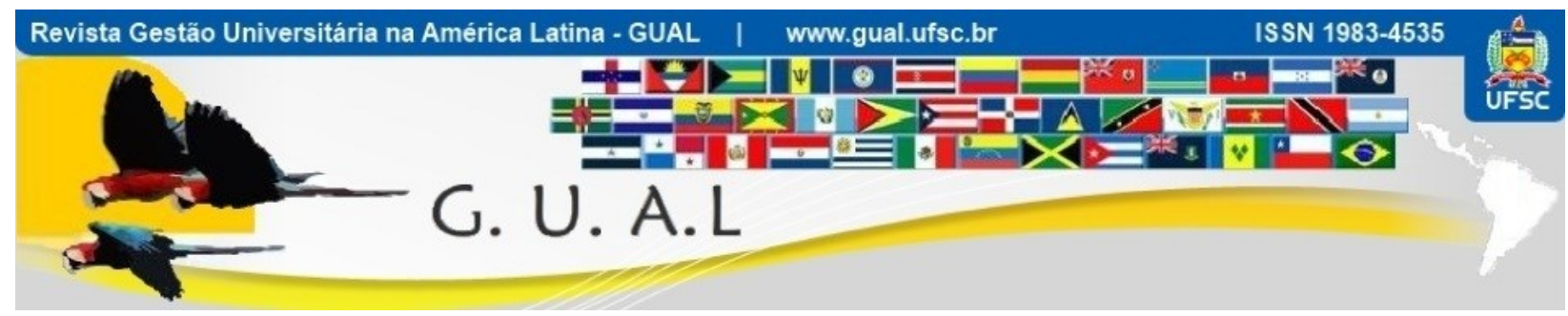

DOI: http://dx.doi.org/10.5007/1983-4535.2017v10n1p62

\title{
O PROCESSO DE EFETIVAÇÃO DO SERVIDOR: UM ESTUDO ACERCA DO ESTÁGIO PROBATÓRIO NAS UNIVERSIDADES
}

\author{
PROCESS SERVER EFFECTIVE: A STUDY ABOUT THE STAGE \\ PROBATIONARY IN UNIVERSITIES
}

Gean Carlos Tomazzoni, Mestrando Universidade Federal de Santa Maria - UFSM gean.tomazzoni@hotmail.com

Vânia Medianeira Flores Costa, Doutora Universidade Federal de Santa Maria - UFSM vania.costa@ufsm.br

Andressa Schaurich dos Santos, Doutoranda Universidade Federal de Santa Maria - UFSM dessaschaurich@gmail.com Denise Espich, Mestranda Universidade Federal de Santa Maria - UFSM deniseespich94@,gmail.com

Talita Gonçalves Posser, Graduanda Universidade Federal de Santa Maria - UFSM talitaposser-@hotmail.com

Recebido em 19/agosto/2015

Aprovado em 05/dezembro/2016

Sistema de Avaliação: Double Blind Review

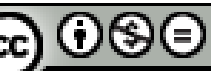

Esta obra está sob uma Licença Creative Commons Atribuição-Uso. 


\title{
RESUMO
}

Este estudo tem como objetivo analisar o processo de avaliação especial de desempenho dos servidores nomeados para os cargos de provimento efetivo em uma instituição pública de ensino superior. A revisão de literatura estruturou-se nas perspectivas da Lei 8.112/1990, que institui o estágio probatório nas autarquias federais brasileiras. O estudo caracteriza-se como um estudo de caso, de natureza descritiva, com o emprego de métodos quantitativos. Os resultados mostraram que no geral, nos cinco fatores de avaliação os servidores apresentaram um desempenho classificado como "dentro do esperado" e "acima do esperado", sendo que a média dentre os fatores variou de 3,143 a 3,872, em uma escala de que vai de 1 a 4 . Apesar deste estudo identificar altos níveis de desempenho dos servidores, tais resultados podem estar associados a comportamentos tendenciosos dos avaliadores em serem menos rigorosos na avaliação. Além disso, constatou-se a pouca exploração do quesito de indicação da necessidade de treinamento para o servidor, o que representa um mecanismo de levantamento de informações para o desenvolvimento de políticas e práticas de treinamento e desenvolvimento voltadas a atender as carências identificadas no processo de avaliação.

Palavras-chave: Estágio probatório. Avaliação especial de desempenho. Servidores públicos. Universidade.

\begin{abstract}
This study is to analyze the special assessment process performance of the named servers for the effective provision of positions in a public institution of higher education. The literature review was structured from the perspectives of Law 8,112 / 1990 establishing the probation in the Brazilian federal authorities. The study is characterized as a case study, descriptive, with the use of quantitative methods. The results showed that overall, the five evaluation factors servers had performance rated "as expected" and "higher than expected", with the average among the factors ranged from 3.143 to 3.872 , on a scale that will 1 to 4 . Although this study identified high levels of performance of servers, such results may be associated with biased behavior of the evaluators in being less strict in the evaluation. In addition, there was a little exploration of this question of training need for appointment to the server, which is an information gathering mechanism for the development of policies and training and development practices geared to meet the needs identified in the assessment process.
\end{abstract}

Key words: Probationary stage. Special performance evaluation. Public servants. University. 


\section{INTRODUÇÃO}

O ingresso em cargo ou emprego público é objetivo profissional de muitos cidadãos brasileiros. Nos últimos anos vêm se intensificando no mercado de trabalho o crescimento de profissionais interessados na investidura em carreiras em organizações do setor público. Segundo Barata (2009), o interesse pelo ingresso no serviço público transpassa a atratividade da estabilidade, e justifica-se principalmente pelas políticas de valorização profissional e pelos altos salários de algumas carreiras de Estado.

No Estado brasileiro, o ingresso de qualquer cidadão a cargos ou empregos de provimento efetivo do serviço público está condicionado ao estágio probatório, como mecanismo de avaliação para a concessão da estabilidade funcional garantida constitucionalmente. O servidor em estágio probatório é titular de competências e tem direito à carreira, mesmo que sua estabilidade ou vitaliciedade nela seja dependente de futura confirmação. Fraga e Martins (2012) entendem o estágio probatório como um determinante de suma importância para investigação e análise dos meios e formas de avaliação do servidor para inserção no serviço público de forma estável.

De forma geral, a busca pela modernização do serviço público, impulsionada, segundo Bresser-Pereira (1996), pelas mudanças ocorridas no cenário nacional a partir da década de 1990, impuseram a necessidade de empreender grande esforço no sentido de migrar do antigo modelo burocrático de administração pública para um modelo gerencial, voltado para a eficiência na prestação e oferta de serviços públicos. A partir de então, conforme Mendes e Teixeira (2000), nas abordagens de gerenciamento dos serviços públicos, buscou-se abrir mão dos sistemas baseados na hierarquia e rigidez burocrática, com práticas patrimonialistas, passando-se a adotar sistemas mais diversificados. Simione (2014) explica que as reformas na administração pública visam reconstruir uma gestão cada vez mais capacitada para responder às solicitações da sociedade e a prestação de serviços com maior qualidade, assim como a elevação do desempenho das Instituições do Estado.

Apesar dos esforços para instituir uma postura ativa na área de recursos humanos na administração pública, Marconi (2005) entende que ainda se dá grande ênfase às funções relacionadas a tarefas administrativas de cunho operacional, como folha de pagamento, informações cadastrais e proposição de regulamentos, relegando para segundo plano as atividades estratégicas de definição de políticas de contratação, capacitação, qualificação, 
remuneração de servidores e o estabelecimento de objetivos e metas alinhados com a organização.

Nesse contexto, Silva e Fadul (2007) explicam que o desafio para a modernização da administração pública deve passar também pela priorização da área de gestão de pessoas. Segundo o autor, diversos projetos precisam ser executados visando tornar os servidores públicos mais competentes para os ideais da reforma gerencial no setor público, dando a área uma postura ativa e capaz de alinhar suas ações de modo a acompanhar a modernização do Estado. Segundo Borges et al. (2010), dentre os problemas vivenciados na área de gestão de pessoas no setor público, destaca-se a contradição atual entre recrutar pessoal para vagas existentes e as dificuldades em reter o pessoal recém-contratado na organização.

Perpassando pela realidade das universidades federais, foco deste estudo, a partir de 2006, com a implementação do Plano de Desenvolvimento da Educação (PDE), que contém programas voltados para a expansão do ensino superior no Brasil, a exemplo do Programa de Apoio a Planos de Reestruturação e Expansão das Universidades Federais (REUNI), o quadro de servidores das universidades apresentou significativo crescimento, necessário para suprir à expansão das atividades, exigindo das Instituições um olhar atencioso ao processo do estágio probatório. Andrade et al. (2014) acreditam que o momento de expansão no qual as universidades passam pode ser "frutífero", desde que haja um bom aproveitamento do quadro de servidores.

Diante do exposto, baseado nas perspectivas da Lei $\mathrm{N}^{\mathrm{o}} 8.112 / 90$ que dispõe sobre o Regime Jurídico Único dos servidores públicos federais, o presente trabalho tem por objetivo analisar o processo de avaliação especial de desempenho dos servidores nomeados para os cargos de provimento efetivo em uma instituição pública de ensino superior.

O estudo acerca do processo do estágio probatório nas carreiras de provimento efetivo em organizações públicas justifica-se pela importância da análise do desempenho profissional dos servidores, na busca permanente pela melhoria na qualidade dos serviços públicos. $\mathrm{Na}$ compreensão de Bresser-Pereira (1996), a importância da reestruturação da administração pública no Brasil foi motivada principalmente pela necessidade da melhoria na prestação dos serviços aos cidadãos. Na mesma perspectiva, Simione (2014) destaca que as novas concepções da administração pública foram impulsionadas pelas críticas ao modelo de bemestar e à gestão baseada nos princípios da racionalidade burocrática. Dessa forma, observa-se 
a relevância de análises organizacionais no que tange à questão do estágio probatório, no atual cenário da educação superior brasileira.

Parte-se, portanto, da importância de compreender como ocorrem os processos de avaliação do estágio probatório, como fator de oportunidade para construção de um modelo de administração pública moderno. Diante disso, pretende-se apresentar uma contribuição teórica e também prática, na incorporação de novas políticas de gestão de pessoas, geradoras de maiores desempenhos, seja pela racionalização de processos gerenciais ou pela melhoria na performance individual do servidor motivado pelo bem-estar no trabalho.

\section{O ESTÁGIO PROBATÓRIO}

A construção do referencial baseia-se nos principais conceitos e contribuição da literatura sobre a temática, incluído as concepções teóricas acerca da Lei 8.112/90 e Lei 12.712/2012 que regulamentam o estágio probatório nas carreiras de técnico-administrativo em educação, docente do ensino superior e docente do ensino básico, técnico e tecnológico.

A estabilidade aos servidores nomeados para cargo de provimento efetivo em virtude de concurso público é um direito garantido pela Constituição Federal do Brasil. De acordo com o art. 41, incluído pela Emenda Constitucional no 19, de 1998, a estabilidade é adquirida após três anos de efetivo exercício, sendo obrigatória durante este período a avaliação especial de desempenho, como condição para efetivação no serviço público. Esse período de préestabilidade, denominado de estágio probatório, é regulamentado pela Lei 8.112 de 1990, que institui o Regime Jurídico dos servidores públicos da união, das autarquias e das fundações públicas federais.

Segundo Modesto (2007), o estágio probatório caracteriza-se como um período de experiência, supervisionado pela administração, destinado a avaliar a adequação do servidor na primeira fase da relação funcional que encetam com o serviço público. Nesse mesmo sentido, Monteiro (2010) compreende este período de tempo como um modelo regimentado de aferição do desempenho, que objetiva avaliar as competências do novo servidor público no exercício de suas atribuições funcionais, observado os critérios estabelecidos na Lei.

De acordo com o Regime Jurídico Único, o servidor em estágio probatório será submetido à avaliação especial de desempenho, buscando verificar a sua aptidão e capacidade. Segundo Modesto (2007), classifica-se como especial para que não se confunda com o processo de avaliação normal de desempenho, realizado periodicamente, com o intuito 
de aferir a qualidade da atuação do quadro geral de colaboradores. De acordo com as perspectivas estabelecidos na Lei 8.112/1990, o servidor é avaliado durante o estágio probatório, com base em 5 macro fatores: assiduidade, disciplina, capacidade de iniciativa, produtividade e responsabilidade. No Quadro 1 apresenta-se os conceitos dos fatores.

\begin{tabular}{|c|l|}
\hline $\begin{array}{c}\text { Fator } \\
\text { Assiduidade }\end{array}$ & Conceito \\
\hline $\begin{array}{c}\text { Avalia a frequência diária do servidor. } \\
\text { Iniciativa }\end{array}$ & $\begin{array}{l}\text { Avalia a capacidade do servidor em tomar providências por conta própria dentro de suas } \\
\text { competências. }\end{array}$ \\
\hline Disciplina & $\begin{array}{l}\text { Avalia o comportamento do servidor quanto aos aspectos de observância aos } \\
\text { regulamentos a chefia. }\end{array}$ \\
\hline Produtividade & $\begin{array}{l}\text { Avalia o volume e a qualidade do trabalho produzido pelo servidor e o atendimento aos } \\
\text { prazos estabelecidos. }\end{array}$ \\
\hline Responsabilidade & $\begin{array}{l}\text { Avalia se o servidor assume as tarefas que lhe são propostas, de maneira a responder pelos } \\
\text { resultados, considerando as possíveis dificuldades. }\end{array}$ \\
\hline
\end{tabular}

Quadro1 Fatores de Avaliação do Estágio Probatório.

Fonte: Baseado na Lei 8.112/1990.

Monteiro (2010), ao analisar o processo do estágio probatório como método de avaliação de desempenho no Ministério Público, considerou que apesar do cumprimento dos requisitos legais, os cinco fatores são carentes de informações e, principalmente, de parâmetros para a realização de uma avaliação mais profunda do desempenho do servidor.

No âmbito do estágio probatório das carreiras de docente do ensino superior e docente do ensino básico, técnico e tecnológico, a aprovação da Lei 12.772 de 2012, que dispõe sobre a reestruturação do plano de carreiras e cargos do magistério federal, trouxe significativas mudanças no processo de avaliação especial de desempenho do docente em estágio probatório.

Com a publicação da Lei em dezembro de 2012, os docentes do magistério federal que ingressaram a partir de $1^{\circ}$ de janeiro de 2013 passaram a ser avaliados por uma comissão de avaliação de desempenho, designada no âmbito de cada Instituição Federal de Ensino (IFEs) (BRASIL, Lei 12.772, 2012). De acordo com o estabelecido na legislação, essa comissão constitui-se por docentes estáveis, com representação da unidade acadêmica de exercício do docente avaliado e do Colegiado do curso no qual o docente ministra o maior número de disciplinas.

Além da alteração da responsabilidade pela avaliação, a Lei também acrescentou novos fatores a serem observados na avaliação do professor em estágio probatório. No Quadro 2 apresenta-se os fatores de avaliação instituídos pela Lei 12.772/2012. 


\begin{tabular}{|c|l|}
\hline $\begin{array}{c}\text { Fator de Avaliação } \\
\begin{array}{c}\text { Adaptação do } \\
\text { professor ao trabalho }\end{array}\end{array}$ & $\begin{array}{l}\text { Vescrição do Fator de Avaliação } \\
\text { atribuições do cargo. }\end{array}$ \\
\hline $\begin{array}{c}\text { Cumprimento dos } \\
\text { deveres e obrigações }\end{array}$ & Verificado a partir da estrita observância da ética profissional. \\
\hline Plano de atividades & $\begin{array}{l}\text { Análise dos relatórios que documentam as atividades científico-acadêmicas e } \\
\text { administrativas programadas no plano de trabalho da unidade de exercício e } \\
\text { apresentadas pelo docente, em cada etapa de avaliação. }\end{array}$ \\
\hline Aptidões & $\begin{array}{l}\text { Assiduidade, disciplina, desempenho didático-pedagógico, capacidade de iniciativa, } \\
\text { produtividade e responsabilidade. }\end{array}$ \\
\hline Programa de & $\begin{array}{l}\text { Participação no Programa de recepção de docentes instituídos pela Instituição } \\
\text { Federal de Ensino. }\end{array}$ \\
\hline Avaliação discente & $\begin{array}{l}\text { Avaliação pelos discentes, conforme normatização própria da Instituição Federal de } \\
\text { Ensino. }\end{array}$ \\
\hline
\end{tabular}

Quadro 2 Fatores de Avaliação dos Docentes em Estágio Probatório.

Fonte: Brasil, Lei 12.772 (2012).

Atendendo aos critérios previstos na Lei 12.772/2012, somados aos fatores estabelecidos na Lei 8.112/90, as Instituições Federais de Ensino precisaram reorganizar seus programas de avaliação especial de desempenho do estágio probatório docente e desenvolver programas de recepção e integração como fatores adicionais da avaliação do estágio probatório, complementados pela análise da execução do plano de atividades científicoacadêmicas e administrativas elaborado pelo docente, conforme predito na legislação.

Finalizado o processo de avaliação especial de desempenho, a comissão constituída para essa finalidade realiza o processo de homologação do estágio probatório. De acordo com o predito na legislação, esse processo deve ocorrer 4 meses antes da finalização do estágio probatório, assim sendo, no $32^{\circ}$ mês de efetivo exercício. A comissão de homologação tem por atribuição analisar o processo de avaliação especial de desempenho do servidor. Não havendo aprovação no estágio probatório, respeitando o direito a ampla defesa e ao contraditório, o servidor deve ser exonerado, ou se estável, reconduzido ao cargo anteriormente ocupado. Havendo aprovação, o servidor adquire a estabilidade no cargo ocupado ao findo do estágio probatório. O servidor só perderá a estabilidade em caso de sentença judicial transitada em julgado ou por processo administrativo disciplinar (BRASIL, Lei 8.112, 1990).

$\mathrm{Na}$ sessão seguinte apresenta-se os procedimentos metodológicos empregados na realização do estudo. 


\section{MÉTODO DO ESTUDO}

Este estudo caracteriza-se como um estudo descritivo, de abordagem metodológica quantitativa. Cabe explicar que se classifica como descritiva, pois segundo Sampieri et al. (2006), os estudos descritivos avaliam dados sobre diversos aspectos, dimensões ou componentes do fenômeno, selecionando questões e medindo ou coletando informações sobre cada uma delas, para melhor descrever o fenômeno pesquisado. A pesquisa é um estudo de caso, onde é investigada uma Instituição Federal de Ensino Superior, localizada no interior do Estado do Rio Grande do Sul. Segundo Fachin (2006), o estudo de caso compreende uma descrição e compreensão completa das relações e dos fatores em cada caso, sem considerar o número de casos pesquisados.

A instituição objeto deste estudo conta com um quadro de 4.698 servidores, divididos entre as carreiras de Docentes da Educação Básica, Técnica e Tecnológica, Docentes do Ensino Superior e Técnico-Administrativos em Educação. Já o corpo discente da Instituição é composto 28.828 estudantes, divididos entre os níveis básico, médio, pós-médio, graduação e pós-graduação e a modalidades ensino presencial e a distância.

Para coleta dos dados utilizou-se a técnica de análise documental, por meio das informações contidas nas fichas de avaliação do estágio probatório dos servidores da universidade objeto do estudo. Para este estudo, foram analisadas as avaliações dos servidores com data de efetivo exercício em de 1 de janeiro de 2012 a 30 de outubro de 2014. Ao total foram coletadas as informações referentes a 938 avaliações, sendo 7 da categoria de docentes do ensino básico, técnico e tecnológico, 273 de docentes do ensino superior e 658 de técnicoadministrativos em educação.

O instrumento de avaliação é composto por três partes. Na primeira sessão, busca-se obter a avaliação do servidor com base nos 5 fatores estabelecidos pela legislação assiduidade, disciplina, capacidade de iniciativa, produtividade e responsabilidade. As afirmações estão estruturadas em uma escala likert de 4, onde 1 representa um desempenho insuficiente e 4 um desempenho acima do esperado no fator. Na segunda sessão busca-se identificar a indicação da chefia quanto a permanência, exoneração, mudança de setor ou necessidade de treinamento do avaliado. Na terceira sessão busca-se identificar as especificidades das necessidades de treinamento identificadas pela chefia. A análise dos dados deu-se a partir do emprego de estatísticas descritivas - médias, moda, mínimo, máximo e desvio-padrão. 
A análise dos dados foi realizada com o auxílio dos softwares "Microsoft Excel" versão 2010, "Statistical Package for Social Sciences" (SPSS) versão 18 e "Statistical Analysis System" (SAS) versão 9.1. Na sessão seguinte apresenta-se os resultados obtidos com a realização do presente estudo.

\section{RESULTADOS}

Nessa sessão, inicialmente, explora-se os resultados do cálculo da média, moda, máximo, mínimo e desvio padrão dos fatores de avaliação para cada categoria de servidor. $\mathrm{Na}$ Tabela 1 apresentam-se os resultados da categoria de docentes do ensino básico, técnico e tecnológico.

Tabela 1 Avaliação dos Docentes do Ensino Básico, Técnico e Tecnológico.

\begin{tabular}{|lccccc}
\multicolumn{1}{c}{ Fator } & Média & Moda & Máximo & Mínimo & Desvio Padrão \\
\hline Assiduidade & 3,143 & 3 & 4 & 3 & 0,3780 \\
Capacidade de Iniciativa & 3,143 & 3 & 4 & 2 & 0,6901 \\
Disciplina & 3,571 & 4 & 4 & 3 & 0,5345 \\
Produtividade & 3,286 & 3 & 4 & 3 & 0,4880 \\
Responsabilidade & 3,571 & 4 & 4 & 3 & 0,5345
\end{tabular}

De acordo com os dados contidos na Tabela 1, percebe-se que para todos os fatores analisados a categoria de docentes do ensino básico, técnico e tecnológico obteve uma média superior a 3, classificando-se como "dentro do esperado" e variando entre 3,143 para os fatores assiduidade e iniciativa e 3,571 para os fatores produtividade e responsabilidade. A moda das avaliações concentrou-se na nota 3 e o desvio padrão variou de 0,3780 a 0,6901 . Na Tabela 2 apresenta-se os resultados da categoria dos docentes do ensino superior.

Tabela 2 Avaliação dos Docentes do Ensino Superior.

\begin{tabular}{|lcccc|c|}
\multicolumn{1}{c}{ Fator } & Média & Moda & Máximo & Mínimo & $\begin{array}{c}\text { Desvio } \\
\text { Padrão }\end{array}$ \\
\hline Assiduidade & 3,842 & 4 & 4 & 3 & 0,3649 \\
\hline Capacidade de Iniciativa & 3,872 & 4 & 4 & 2 & 0,3457 \\
\hline Disciplina & 3,846 & 4 & 4 & 2 & 0,3715 \\
\hline Produtividade & 3,780 & 4 & 4 & 2 & 0,4322 \\
\hline Responsabilidade & 3,842 & 4 & 4 & 3 & 0,3649
\end{tabular}

Para a categoria de docentes do ensino superior a média das avaliações concentrou-se próxima a nota 4, classificada como "acima do esperado". A maior média foi 3,872, atribuída ao fator capacidade de iniciativa, enquanto que a menor foi 3,780 para o fator produtividade. Para todos os fatores a moda foi 4 e o desvio padrão variou entre 0,3457 para o fator 
capacidade de iniciativa e 0,4322 para produtividade. Na Tabela 3 apresentam-se os resultados da categoria de técnico-administrativos em educação.

Tabela 3 Avaliação dos Técnico-Administrativos em Educação.

\begin{tabular}{llllll} 
Fator & Média & Moda & Máximo & Mínimo & Desvio Padrão \\
\hline Assiduidade & 3,857 & 4 & 4 & 1 & 0,3794 \\
Capacidade de Iniciativa & 3,825 & 4 & 4 & 1 & 0,4325 \\
Disciplina & 3,749 & 4 & 4 & 1 & 0,5315 \\
Produtividade & 3,767 & 4 & 4 & 1 & 0,5018 \\
Responsabilidade & 3,847 & 4 & 4 & 1 & 0,4120
\end{tabular}

Analisando-se a Tabela 3, verifica-se que na categoria dos técnico-administrativos em educação a média para todos os fatores também aproximou-se da nota 4 , indicando que os fatores foram avaliados como "acima do esperado". A moda concentrou-se na nota 4 e o desvio padrão variou entre 0,3794 para o fator assiduidade e 0,5315 para disciplina.

Em geral, para todas as categorias caracterizam-se como bons resultados para a instituição, que possui um quadro de novos servidores altamente qualificados. Eby et al. (1999) destaca que os trabalhadores mais competentes, devido à sua habilidade de adaptação, conhecimentos gerais e senso de responsabilidade costumam ser mais motivados e que esta motivação afeta positivamente a satisfação e o comprometimento. Dessa forma, trabalhadores mais competentes tendem a ser mais satisfeitos, comprometidos, reduzindo as taxas de absenteísmo e turnover.

$\mathrm{Na}$ compreensão de Dieese (2006) a assiduidade representa um dos principais indicadores utilizado pelas empresas para mensurar a produtividade. Para o autor, a importância da assiduidade como indicador individual ou coletivo é devido principalmente aos quadros reduzidos e enxutos do atual modelo flexível organizacional, pois a ausência do funcionário indistintamente de seu motivo pode trazer instantânea redução na produtividade, qualidade dos produtos e serviços entregues e da satisfação do cliente.

Para complementar a análise das competências e aptidões dos servidores submetidos à avaliação especial de desempenho do estágio probatório, aborda-se na sequência os resultados das frequências das classificações individualizadas para cada fator de avaliação. Na Tabela 4 apresenta-se as frequências encontradas para cada fator da avaliação especial de desempenho. 
Tabela 4 Fatores da Avaliação Especial de Desempenho.

\begin{tabular}{|c|c|c|c|c|c|c|}
\hline \multirow[b]{2}{*}{ ASSIDUIDADE } & \multicolumn{2}{|c|}{$\begin{array}{l}\text { Docentes do Ensino } \\
\text { Superior }\end{array}$} & \multicolumn{2}{|c|}{$\begin{array}{l}\text { Docentes do Ensino } \\
\text { Básico, Técnico e } \\
\text { Tecnológico }\end{array}$} & \multicolumn{2}{|c|}{$\begin{array}{c}\text { Técnico-Administrativos } \\
\text { em Educação }\end{array}$} \\
\hline & Frequência & Percentual & $\begin{array}{l}\text { Frequênci } \\
\text { a }\end{array}$ & Percentual & $\begin{array}{c}\text { Frequênci } \\
\text { a }\end{array}$ & Percentual \\
\hline Insuficiente & 0 & $0 \%$ & 0 & $0 \%$ & 1 & $0,2 \%$ \\
\hline Regular & 0 & $0 \%$ & 0 & $0 \%$ & 4 & $0,6 \%$ \\
\hline Dentro do Esperado & 43 & $15,8 \%$ & 6 & $85,7 \%$ & 83 & $12,6 \%$ \\
\hline Acima do Esperado & 230 & $84,2 \%$ & 1 & $14,3 \%$ & 570 & $86,6 \%$ \\
\hline TOTAL & 273 & $100 \%$ & 7 & $100 \%$ & 658 & $100 \%$ \\
\hline INICIATIVA & Frequência & Percentual & $\begin{array}{c}\text { Frequênci } \\
\text { a }\end{array}$ & Percentual & $\begin{array}{c}\text { Frequênci } \\
\text { a }\end{array}$ & Percentual \\
\hline Insuficiente & 0 & $0 \%$ & 0 & $0 \%$ & 4 & $0,6 \%$ \\
\hline Regular & 1 & $0,4 \%$ & 1 & $14,3 \%$ & 19 & $2,9 \%$ \\
\hline Dentro do Esperado & 33 & $12,1 \%$ & 4 & $57,1 \%$ & 115 & $17,5 \%$ \\
\hline Acima do Esperado & 239 & $87,5 \%$ & 2 & $28,6 \%$ & 520 & $79 \%$ \\
\hline TOTAL & 273 & $100 \%$ & 7 & $100 \%$ & 658 & $100 \%$ \\
\hline DISCIPLINA & Frequência & Percentual & $\begin{array}{c}\text { Frequênci } \\
\text { a }\end{array}$ & Percentual & $\begin{array}{c}\text { Frequênci } \\
\text { a }\end{array}$ & Percentual \\
\hline Insuficiente & 0 & $0 \%$ & 0 & $0 \%$ & 1 & $0,2 \%$ \\
\hline Regular & 1 & $0,4 \%$ & 0 & $0 \%$ & 11 & $1,7 \%$ \\
\hline Dentro do Esperado & 40 & $14,7 \%$ & 3 & $42,9 \%$ & 90 & $13,7 \%$ \\
\hline Acima do Esperado & 232 & $85 \%$ & 4 & $57,1 \%$ & 556 & $84,5 \%$ \\
\hline TOTAL & 273 & $100 \%$ & 7 & $100 \%$ & 658 & $100 \%$ \\
\hline PRODUTIVIDADE & Frequência & Percentual & $\begin{array}{c}\text { Frequênci } \\
\text { a }\end{array}$ & Percentual & $\begin{array}{c}\text { Frequênci } \\
\text { a }\end{array}$ & Percentual \\
\hline Insuficiente & 0 & $0 \%$ & 0 & $0 \%$ & 4 & $0,6 \%$ \\
\hline Regular & 2 & $0,7 \%$ & 0 & $0 \%$ & 12 & $1,8 \%$ \\
\hline Dentro do Esperado & 56 & $20,5 \%$ & 5 & $71,4 \%$ & 117 & $17,8 \%$ \\
\hline Acima do Esperado & 215 & $78,8 \%$ & 2 & $28,6 \%$ & 525 & $79,8 \%$ \\
\hline TOTAL & 273 & $100 \%$ & 7 & $100 \%$ & 658 & $100 \%$ \\
\hline RESPONSABILIDADE & Frequência & Percentual & $\begin{array}{c}\text { Frequênci } \\
\text { a }\end{array}$ & Percentual & $\begin{array}{c}\text { Frequênci } \\
\text { a }\end{array}$ & Percentual \\
\hline Insuficiente & 0 & $0 \%$ & 0 & $0 \%$ & 2 & $0,3 \%$ \\
\hline Regular & 0 & $0 \%$ & 0 & $0 \%$ & 7 & $1,1 \%$ \\
\hline Dentro do Esperado & 43 & $15,8 \%$ & 3 & $42,9 \%$ & 81 & $12,3 \%$ \\
\hline Acima do Esperado & 230 & $84,2 \%$ & 4 & $57,1 \%$ & 568 & $86,3 \%$ \\
\hline TOTAL & 273 & $100 \%$ & 7 & $100 \%$ & 658 & $100 \%$ \\
\hline
\end{tabular}

De acordo com os dados da Tabela 4, verifica-se que para o fator de assiduidade a maioria dos docentes do ensino superior e técnico-administrativos submetidos à avaliação do estágio probatório apresentou desempenho classificado como "acima do esperado", com $84,2 \%$ e $86,6 \%$ dos participantes respectivamente. Na categoria dos docentes do ensino básico, técnico e tecnológico a maioria dos avaliados recebeu nota 3, representado um desempenho classificado como "dentro do esperado" neste fator, com $85,7 \%$ dos participantes.

Analisando-se os dados referentes ao fator capacidade de iniciativa, é possível afirmar que a maioria dos docentes do ensino superior e os técnico-administrativos obteve nota 4, $87,5 \%$ e $79 \%$ dos participantes respectivamente, representado um desempenho "acima do 
esperado". Da mesma forma, a maioria dos docentes do ensino básico, técnico e tecnológico apresentou desempenho classificado como "dentro do esperado", com 57,1\% dos participantes deste estudo.

Quanto ao fator disciplina, constata-se que $85 \%$ dos docentes do ensino superior, $57,1 \%$ dos docentes do ensino básico, técnico e tecnológico e $84,5 \%$ dos técnicoadministrativos em educação submetidos à avaliação especial de desempenho do estágio probatório apresentaram um desempenho "acima do esperado" neste fator.

Com relação ao fator produtividade, identificou-se que a maioria dos docentes do ensino superior e técnico-administrativos obteve nota máxima para o fator produtividade na avaliação especial de desempenho, com 78,8\% dos docentes e 79,8\% dos técnicoadministrativos participantes, indicando que no geral esses servidores apresentaram um desempenho "acima do esperado" para o fator produtividade. Na categoria docentes do ensino básico, técnico e tecnológico a predominância foi para a nota 3, que caracteriza um desempenho "dentro do esperado", com 71,4\% dos participantes.

Os dados da Tabela 4 evidenciam que nas três categorias de servidores, a maioria dos participantes obteve nota máxima para o fator responsabilidade, o que caracteriza um desempenho "acima do esperado" neste fator, com $84,2 \%$ dos docentes do ensino superior, $57,1 \%$ dos docentes do ensino básico, técnico e tecnológico e $86,3 \%$ dos técnicoadministrativos em educação.

Finalizando a avaliação dos fatores de competência, pré-estabelecidos na Lei, os avaliadores indicam o parecer quanto à permanência, ou não, do servidor no setor, necessidade de treinamento, remoção do setor, ou a exoneração. Na Tabela 5 apresenta-se os resultados dos pareceres dos avaliadores para cada categoria de servidor. Cabe destacar que nesta etapa, os avaliadores podem optar por mais de uma opção, o que justifica o resultado total não indicar a soma das opções individualizadas.

Tabela 5 Parecer da Avaliação Especial de Desempenho.

\begin{tabular}{|lccc|}
\hline \multicolumn{1}{c}{ Parecer } & $\begin{array}{c}\text { Docentes do ensino } \\
\text { superior }\end{array}$ & $\begin{array}{c}\text { Docentes do ensino } \\
\text { básico, técnico e } \\
\text { tecnológico }\end{array}$ & $\begin{array}{c}\text { Técnico- } \\
\text { Administrativos em } \\
\text { educação }\end{array}$ \\
\hline $\begin{array}{l}\text { Prequência } \\
\text { Sermanecer no setor }\end{array}$ & 272 & $\begin{array}{c}\text { Frequência } \\
\text { Frequência }\end{array}$ & 641 \\
\hline Remanejado para outro setor & 1 & 7 & 33 \\
Exonerado & 0 & 0 & 8 \\
Outras medidas & 0 & 0 & 0 \\
TOTAL & 0 & 0 & 3 \\
\hline
\end{tabular}


De acordo com os dados da Tabela 5, percebe-se que os pareceres dos avaliadores indicam predominantemente a permanência do servidor no setor, com destaque para as duas categoriais docentes. $\mathrm{Na}$ categoria de técnico-administrativos em educação a permanência no setor foi recomendada por aproximadamente $97 \%$ dos avaliadores, porém houve uma maior representatividade da indicação de necessidade de treinamento.

Analisando-se os dados apresentados acima, constata-se que de forma geral, as avaliações especiais de desempenho no âmbito do caso estudado caracterizam-se como um processo que avalia o servidor de forma positiva, garantindo a concessão da estabilidade com a aprovação do estágio probatório. Nesse sentido, Modesto (2007) manifesta a preocupação com a efetividade do estágio probatório como um processo de avaliação real do servidor. Segundo o autor, é essencial que os avaliadores exerçam seu papel de forma comprometida para garantir que a avaliação não represente apenas uma etapa "fria" para o alcance da estabilidade do servidor, prejudicando a longo prazo o desempenho da administração pública na prestação de serviços a sociedade.

Para Paula et al. (2010) as rotinas burocráticas, os prazos, o cumprimento de todos os procedimentos legais que precisam ser observados em uma organização pública, muitas vezes não fomentam um momento de interação entre avaliador e avaliado que garante uma avaliação efetiva. Lucas et al. (2010) esclarece que a avaliação de desempenho é vista como um processo que gera informações importantes para a administração pública, mas para o autor, a utilização da avaliação de desempenho na administração pública pode não representar uma forma confiável de fornecer informações válidas, pois, segundo os autores, fatores como tendência a leniência podem fazer dela apenas uma formalidade. Paula et al. (2010) compreende que em diversos momentos o processo de avaliação de desempenho na administração pública cumpre apenas um requisito legal, ignorando a importância da realização de uma avaliação de desempenho equitativa e uniforme, que resulte em impactos mais diversificados e produtivos para a Instituição.

Diante deste contexto, Lucas et al. (2010) explica que entre os desafios da avaliação de desempenho na administração pública existe uma tendência dos avaliadores em serem menos rigorosos na avaliação, seja para evitar conflitos ou para fazer jogos políticos, descaracterizando o objetivo de aferição do desempenho do servidor. Além da necessidade do compromisso para com o processo, Vilhena et al. (2006) comenta que é necessário também que avaliador e avaliado compreendam que a avaliação não representa uma ameaça a sua 
estabilidade, evidenciando-se um importante mecanismo para o reconhecimento de seu desempenho e identificação de possíveis necessidades de capacitação.

Buscando mapear as necessidades de treinamento identificadas pelas chefias no processo de avaliação do estágio probatório, na Figura 1 ilustra-se as principais demandas de treinamento solicitadas pelos avaliadores.

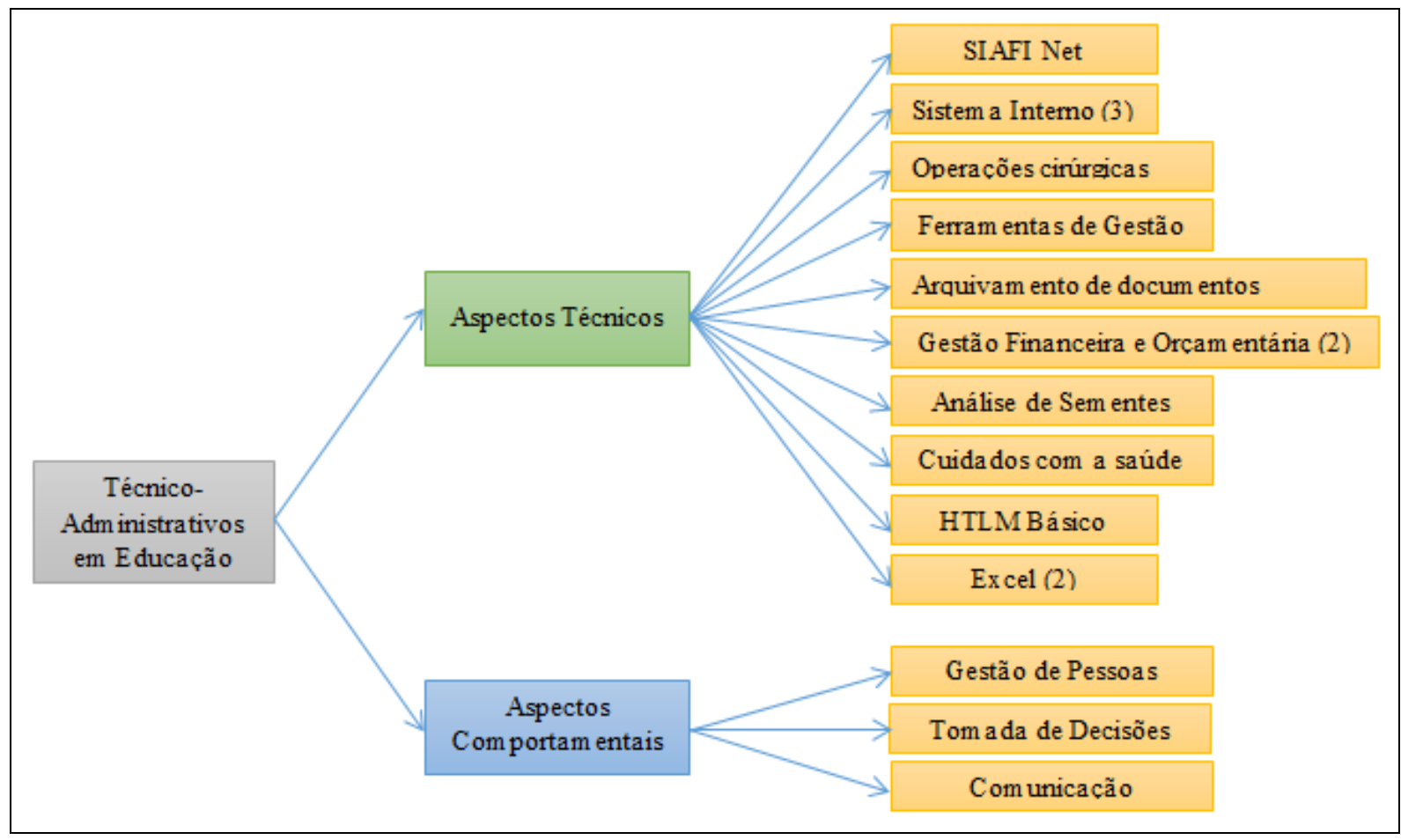

Figura 1 Necessidades de Treinamento.

Conforme ilustrado na Figura 1, identifica-se que as demandas de treinamento solicitadas pelos avaliadores do estágio probatório concentram-se principalmente em aspectos técnicos relacionados à informática, sistemas de informação e conhecimentos específicos relacionados ao cargo do avaliado. Nos aspectos comportamentais destacam-se três demandas de treinamento relativas à gestão de pessoas, processo de tomada de decisão e comunicação.

Salienta-se que para as duas categorias de docentes não houve nenhuma indicação de treinamento por parte dos avaliadores. Assim, verifica-se que ainda é pouco explorado a indicação de necessidades de treinamento, o que dificulta que a gestão da Instituição consiga planejar e organizar capacitações voltadas a suprir as necessidades específicas de treinamento para os novos servidores. Modesto (2002) corrobora com esse pensamento ao explicar que o estágio probatório deve caracteriza-se como uma etapa centrada na atenção aos servidores que apresentam dificuldades no desempenho de suas atividades, visando proporcionar 
mecanismos que consigam qualificá-lo para o desempenho de suas funções. Ainda, segundo o autor, o grande desafio para a administração pública é a realização um processo avaliativo, contínuo, ordenado, garantidor dos direitos do servidor, mas ao mesmo tempo capaz de depurar resultados que identifiquem os agentes que realmente estão aptos ao desempenho de funções públicas.

\section{CONSIDERAÇÕES FINAIS}

Este estudo teve como objetivo analisar o processo de avaliação especial de desempenho dos servidores nomeados para os cargos de provimento efetivo em uma instituição pública de ensino superior. Para alcançar este objetivo, foram analisados 938 processos de avaliação especial de desempenho de servidores - docentes do ensino superior, docentes do ensino básico, técnico e tecnológico e técnico-administrativos em educação - de uma instituição brasileira pública de ensino superior.

Os resultados mostraram que no geral, nos cinco fatores os servidores apresentaram um desempenho classificado como "dentro do esperado" e "acima do esperado", sendo que a média dentre os fatores variou de 3,143 a 3,872, em uma escala de que vai de 1 a 4 . Apesar deste estudo identificar altos níveis de desempenho dos servidores, tais resultados podem estar associados a comportamentos tendenciosos dos avaliadores em serem menos rigorosos na avaliação.

Nesse contexto, autores como Modesto (2007) e Fraga e Martins (2012) questionam a efetividade do estágio probatório com processo de avaliação e compreendem o papel consciente do avaliador como um imperativo na consolidação de programas bem-sucedidos de avaliação especial de desempenho do estágio probatório. Identificou-se que menos de $4 \%$ dos avaliadores indicaram necessidades de treinamentos para o servidor, que em linhas gerais, demonstra que ainda é pouco explorado esse quesito do processo de avaliação. É também importante que critérios qualitativos sejam implementados, possibilitando uma análise mais profunda do desempenho do servidor.

Sugere-se que outras pesquisas sejam conduzidas utilizando a mesma temática, no intuito de comparar os resultados com outras instituições públicas do país. Também é importante a realização de estudos qualitativos com objetivo de investigar em profundidade como as chefias compreendem e realizam a avaliação de seus servidores em estágio probatório. Destaca-se como limitações o fato de ser um caso único, o que impossibilita a 
generalização dos resultados para toda a população. Como contribuições, este estudo deixa um legado ao avançar na explicação acerca da avaliação especial de desempenho do estágio probatório nas carreiras de natureza pública.

\section{REFERÊNCIAS}

ANDRADE, D. C. T.; PENHA, R.; RAMOS, H. R. Um estudo sobre a percepção de servidores públicos acerca do nível de socialização organizacional. In: ENCONTRO NACIONAL DA ANPAD, 38., Rio de Janeiro, 2014. Anais... Rio de Janeiro, 2014.

BARATA, A. M. Questões relevantes sobre concurso público. Revista do Ministério Público do Estado do Pará, Belém, ano 4, volume 1, p. 41-55, dez. 2009.

BORGES, L. O.; SILVA, F. H. V. C.; MELO, S. L.; OLIVEIRA, A. S. Re-construção e validação de um inventário de socialização organizacional. Revista de Administração Mackenzie, v. 11, n. 4, p. 4-37, 2010.

BRASIL. Lei n. 8.112, de 11 de dezembro de 1990. Dispõe sobre o regime jurídico dos servidores públicos civis da União, das autarquias e das fundações públicas federais. Diário Oficial [da] República Federativa do Brasil, Brasília, DF, 19 abr. 1991. Disponível em: $<$ https://www.planalto.gov.br/ccivil_03/leis/18112cons.htm>. Acesso em 24 ago. 2014.

BRASIL. Lei n. 12.772, de 28 de dezembro de 2012. Dispõe sobre a estruturação do plano de carreiras e cargos de Magistério Federal; sobre a carreira do Magistério Superior. Diário Oficial [da] República Federativa do Brasil, Brasília, DF, 21 dez. 2012. Disponível em: $<$ http://www.planalto.gov.br/ccivil_03/_ato2011-2014/2012/lei/112772.htm>. Acesso em 24 ago. 2014.

BRESSER-PEREIRA, L. C. A reforma da Administração Pública: Crise Econômica e Reforma do Estado no Brasil. São Paulo, Editora 34, 1996.

DIEESE. Participação dos trabalhadores nos lucros ou resultados das empresas 2005. Estudos e Pesquisas, ano 3, n. 22, agosto de 2006. Disponível em:

$<$ http://www.dieese.org.br/estudosepesquisas/2006/estpesq22 plr.pdf $>$. Acesso em 15 out. 2014.

EBY, L. T.; FREEMAN, D. M.; RUSCH, M. C.; LANCE, C. E. Motivational bases of affective organizational commitment: a partial test of an integrative theoretical model. Journal of Occupational and Organizational Psychology, v.72, p.463-483, 1999.

FACHIN, O. Fundamentos de metodologia. 5. ed. São Paulo: Saraiva, 2006.

FRAGA, C. G. S.; MARTINS, J. R. A (in)eficácia do estágio probatório do servidor público como instrumento de avaliação da Administração Pública Municipal. Revista do Instituto do Direito Brasileiro, v. 1, n. 10, 2, p. 5991-6031, 2012. 
LUCAS, A. C.; TEIXEIRA, H. J.; JUNDURIAN, M. A.; DANTAS, S. S. Desafios do processo de avaliação de desempenho na administração pública: um estudo de caso na Prefeitura Municipal de São Paulo. In: ENCONTRO DE ADMINISTRAÇÃO PÚBLICA E GOVERNANÇA, 4., Vitória, 2010. Anais...Vitória, 2010.

MARCONI, N. Políticas integradas de recursos humanos para o setor público. In: LEVY, E.; DRAGO, P. A., (Orgs.), Gestão Pública no Brasil Contemporâneo. São Paulo: Edições Fundap, 2005.

MENDES, V. L.P. S. TEIXEIRA, F. L. C. O Novo Gerencialismo e os Desafios para a Administração Pública. In: ENCONTRO NACIONAL DA ANPAD, 25., Campinas, 2000. Anais... Campinas, 2000.

MODESTO, P. Estágio Probatório: Questões Controversas. Revista Diálogo Jurídico, Salvador, n. 12, p. 1-28, mar. 2002.

MODESTO, P. Estágio Probatório: Questões Controversas. Revista Eletrônica de Direito de Estado, Salvador, n. 10, p. 1-27, abr./jun. 2007.

MONTEIRO, M.B. Estágio Probatório como Método de Avaliação do Servidor: Estudo de caso no Ministério Público Gaúcho. 2010. 69 f. Trabalho de Conclusão de Curso (Graduação em Administração)-Universidade Federal do Rio Grande do Sul, Porto Alegre, 2010.

PAULA, F.; FEUERSCHUTTE, S. G.; PEREIRA, R. S. A avaliação de desempenho no Ministério Público de Santa Catarina: possibilidades para a atuação estratégica da área de gestão de pessoas na organização. In: ENCONTRO DE ADMINISTRAÇÃO PÚBLICA E GOVERNANÇA, 4., Vitória, 2010. Anais...Vitória, 2010.

SAMPIERI, R. H.; COLLADO, C. H.; LUCIO, P. B. Metodologia de Pesquisa. São Paulo: McGraw-Hill, 2006.

SILVA, L. P.; FADUL, E. M. C. Modernização em Organizações Públicas: Um Descompasso Entre Processos de Modernização Organizacional e Gestão de Pessoas. In: ENCONTRO DE GESTÃO DE PESSOAS E RELAÇÕES DE TRABALHO, 1., Natal, 2007. Anais...Natal, 2007.

SIMIONE A. A. A modernização da gestão e a governança no setor público em Moçambique. Revista de Administração Pública, v. 48, n. 3, Rio de Janeiro, p. 551-570, 2014.

VILHENA, R.; MARTINS, H. F.; MARINI, C.; GUIMARÃES, T. B.O Choque de Gestão em Minas Gerais: políticas da gestão pública para o desenvolvimento. Ed. UFMG, 2006. 